\title{
Laparoscopic pyelolithotomy in a horseshoe kidney
}

\author{
Erkan Ölçücüoğlu ${ }^{1}$, Ahmet Çamtosun ${ }^{1}$, Sait Biçer ${ }^{1}$, Ahmet Murat Bayraktar²
}

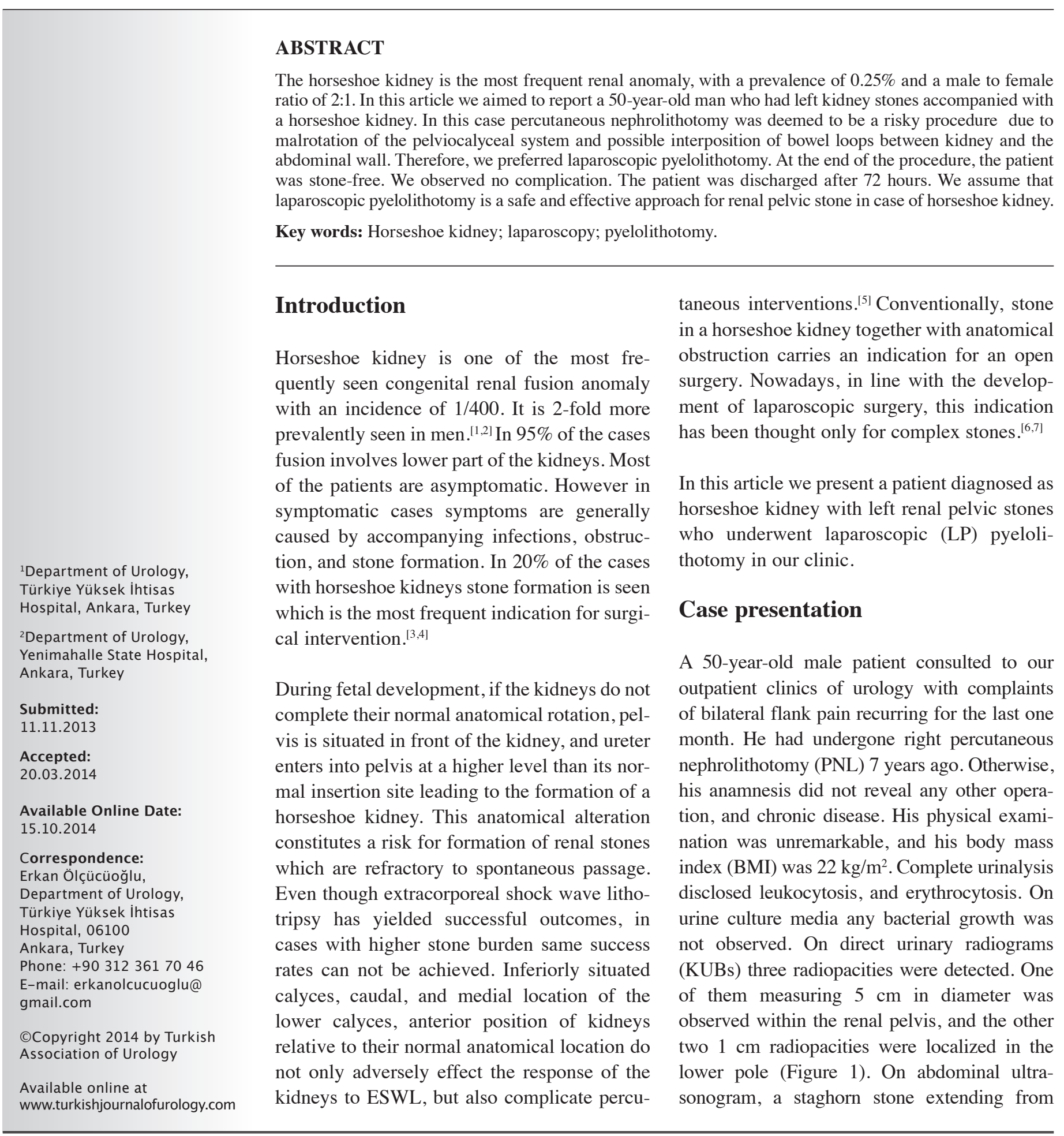




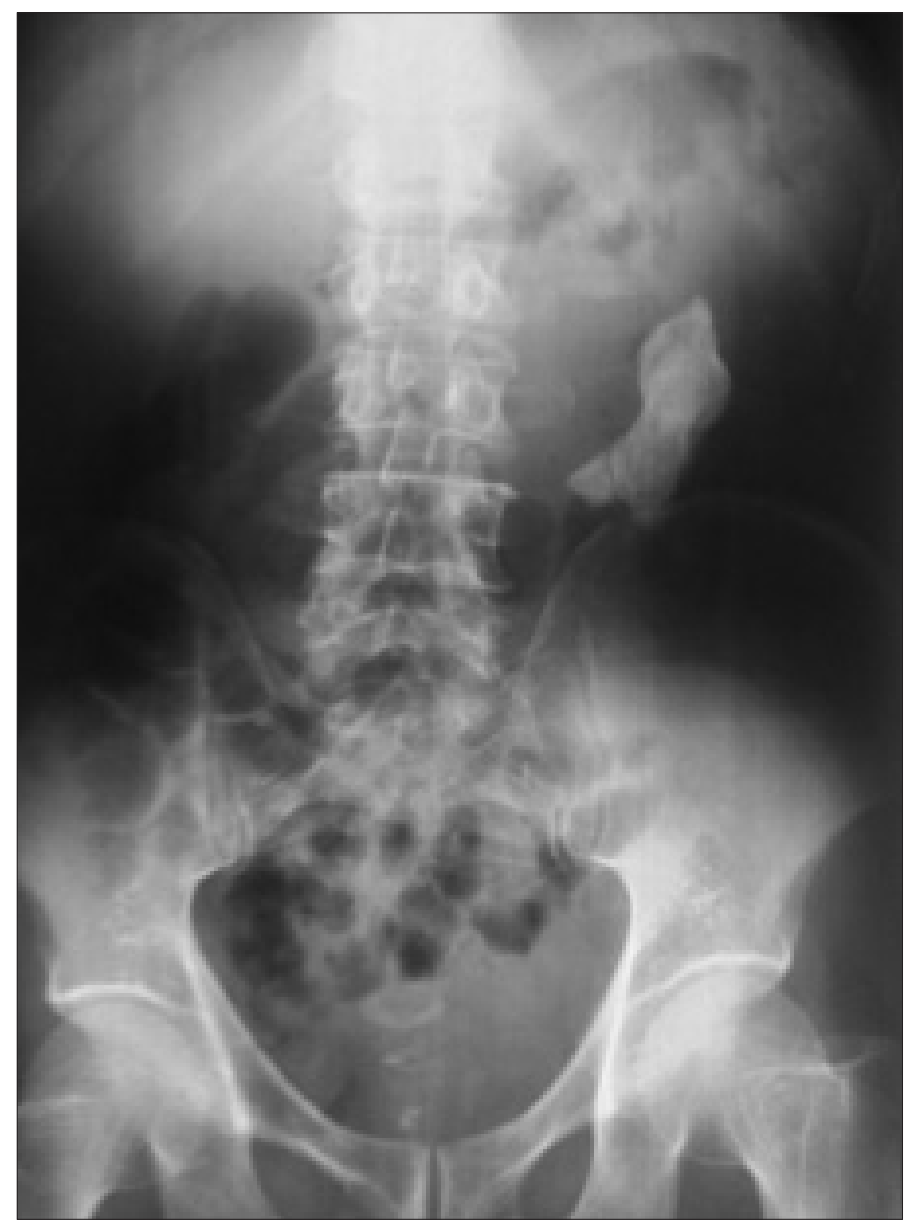

Figure 1. Preoperative direct urinary system radiogram

the middle portion of the left kidney up to the lower pole, and moderate-severe dilatation of the left renal collecting system were observed. On IVP, both kidneys were functional, and an image consistent with horseshoe kidney was detected. Besides, a total of three radiopacities were observed on urograms. One of them had a diameter of $5 \mathrm{~cm}$, and filled the left renal pelvis completely, the other two radiopacities were localized in the lower pole the largest one being $1 \mathrm{~cm}$ in diameter. (Figure 2). On abdominal computed tomograms (CTs), an image consistent with horseshoe kidney with united lower poles in front of the aorta, and a normal right renal collecting system were observed. In addition severely hydronephrotic left kidney together with three radiopacities situated along a segment beginning from proximal ureter up to the renal pelvis, the largest one with dimensions of 55 x $25 \mathrm{~mm}$ were found (Figure 3). Surgical technique to be applied was explained to the patient, and his informed consent was obtained. Then he was hospitalized in our clinic for laparoscopic lithotripsy.

\section{Surgical technique}

Under general anesthesia, while the patient laid down on his right side, a Veress needle was inserted at the level of umbilicus

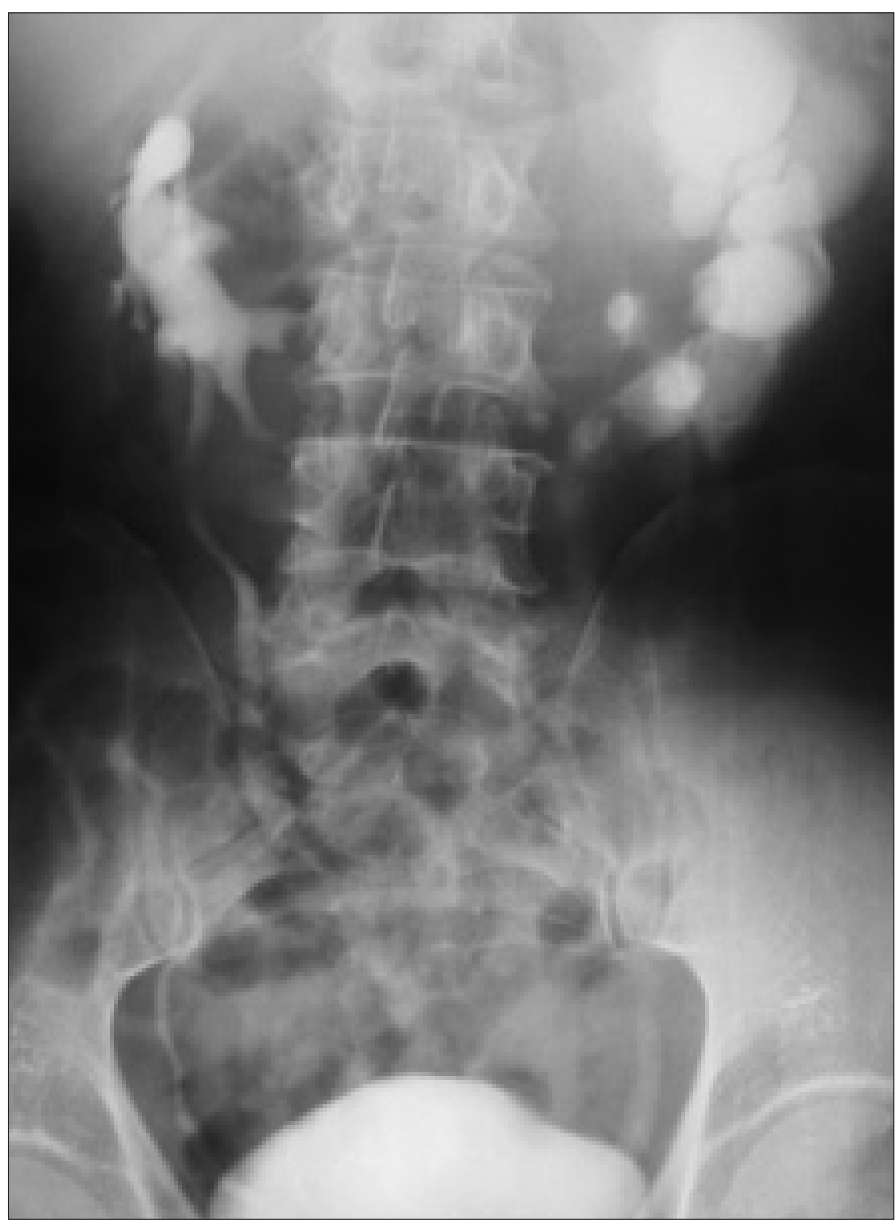

Figure 2. Intravenous pyelogram obtained at $15 . \mathrm{min}$

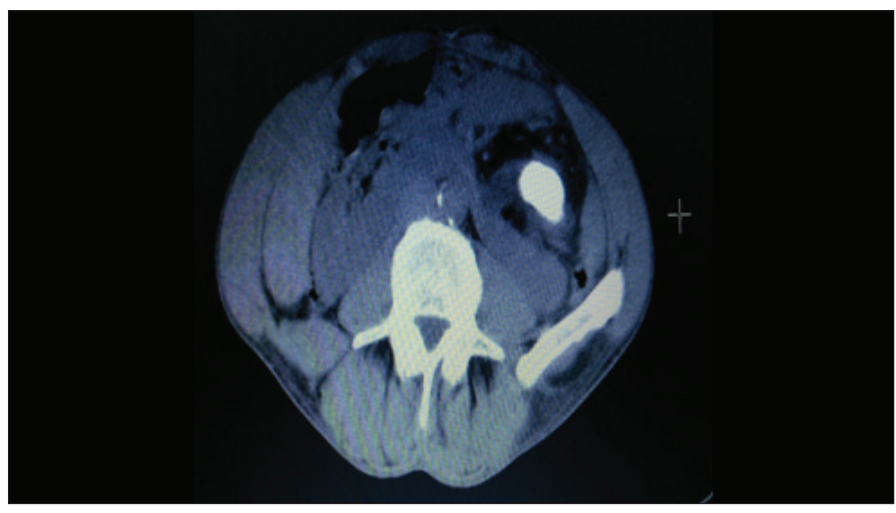

Figure 3. Computed tomography scan of horseshoe kidney with nephrolithiasis

through the lateral edge of the rectus abdominis muscle, and intraperitoneal cavity was entered. Carbon dioxide was insufflated into the peritoneal cavity to create pneumoperitoneum. With the aid of Visiport ${ }^{\circledR}$ Spin Window, intraabdominal cavity was entered through a $12 \mathrm{~mm}$-trocar. A total of 3 trocars with a diameter of $10 \mathrm{~mm}$ was placed. Priorly, descending segment 

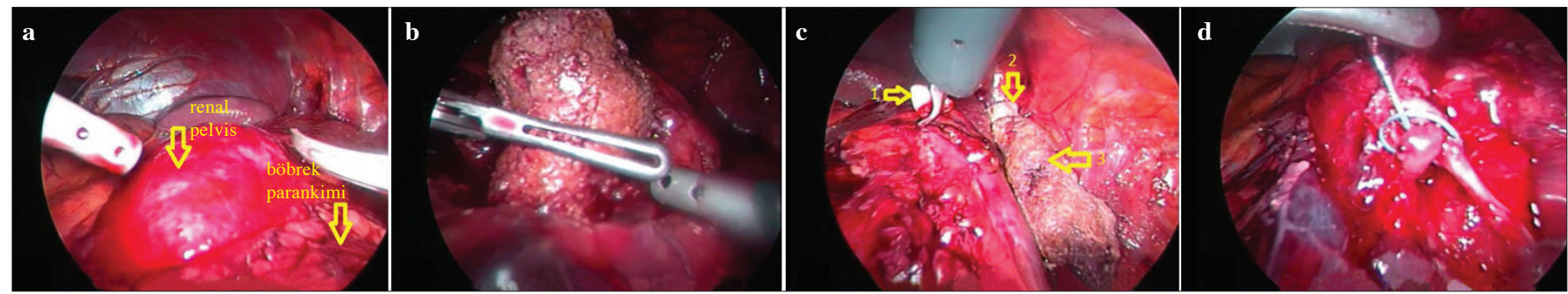

Figure 4. a-d. Intraoperative photographs. (a) Dissection of the renal pelvis. (b) Extraction of the stone from the renal pelvis. (c) Removal of three intrarenal stones. (d) Suturing of renal pelvis

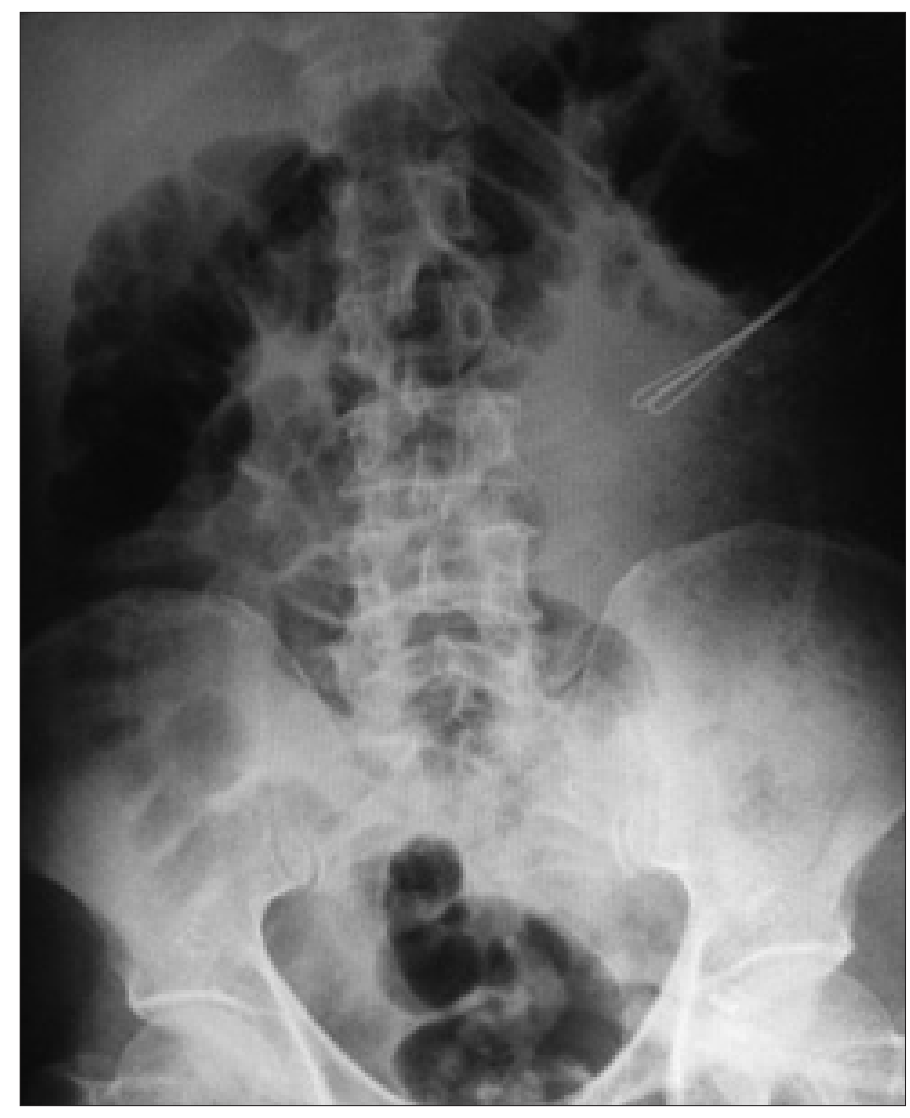

Figure 5. Postoperative direct urinary system radiogram

of the left colon was separated from the Toldt membrane down to the splenic flexura, and retroperitoneal space was entered. Gerota fascia was opened, and renal pelvis was dissected, and explored. (Figure 4a). Renal pelvis was incised vertically for 3 $\mathrm{cm}$. Then firstly renal pelvic stone measuring $5 \mathrm{~cm}$ in diameter, then 2 lower pole stones the largest one being $1 \mathrm{~cm}$ in diameter were held with a laparoscopic grasper, and taken out. (Figure $4 \mathrm{~b}, \mathrm{c})$. Pelvis was closed with continuous 4.0 vicryl sutures (Figure 4d). Any intraoperative complication did not develop. Stones were placed in an endobag, and trocar access tract was dilated for $1 \mathrm{~cm}$ so as to take the stones outside. A drain was placed inside the loge.
Operative time, and duration of hospitalization were 150 min, and 3 days, respectively. Total amount of bleeding was $100 \mathrm{cc}$. Any procedural complication was not detected, and complete stone-free status was achieved. Postoperative control radiograms did not reveal any residual stone fragments (Figure 5).

\section{Discussion}

Stone disease is the most frequently encountered problem in horseshoe kidneys. In calculous kidneys with congenital anomalies, treatment is more challenging, and altered renal anatomy requires different anatomical approaches. These management modalities include ESWL, PNL, flexible ureterorenoscopy, laparoscopy, and open surgery. Even though ESWL and PNL are most frequently used methods in the treatment of stone disease, suboptimal results have been obtained in some circumstances.

Stone-free rates in horse-shoe kidneys after ESWL procedures have ranged between 28, and 80 percent. Besides ESWL can be safely performed for stones smaller than $2 \mathrm{~cm}$, and in patients with lighter stone-burden whose urinary drainage is not blocked ${ }^{[8,9]}$ For patients with relatively heavier stone burden most of the time, an additional treatment modality can be required apart from ESWL. ${ }^{[10,11]}$ Our case had a heavier stoneburden $(55 \times 25 \mathrm{~mm})$ so we didn't prefer ESWL.

In anomalous kidneys, laparoscopy has been used alone or in combination with other endoscopic procedures. Laparoscopic management of stone disease in a patient with a horseshoe kidney was firstly performed by Maheshwari et al in 2004. ${ }^{[12]}$ Though for renal stones measuring $2 \mathrm{~cm}$ or greater, PNL is a proper treatment alternative, in anomalous kidneys it can lead to serious complications. ${ }^{[13-16]}$ Unusual anatomical positions of anomalous kidneys (medial location of renal pelvis, and lower pole in horseshoe kidneys might prevent approach of nefroscope to these anatomical structures during PNL), abnormal renal, and calyceal orientation, pathological communications 
between calices, collecting system, and upper ureteral segment, presence of aberrant vessels, relative immobility of the horseshoe kidney which restricts maneuverability of rigid instruments, and abnormal anatomical relationship of horseshoe kidney with other adjacent organs, and especially with intestinal system result in development of complications, and procedural failure. ${ }^{[13]}$ During PNL procedure performed for the extraction of stone(s) in a horseshoe kidney, one should be very careful about abnormal relationship of pelviocalyceal system with surrounding adjacent organs, and refrain from the risk of injuring neighbouring organs especially the colon. ${ }^{[14]}$

Since flexible URS has a higher success rates for stones smaller than $2 \mathrm{~cm}$, we didn't prefer to use this system for our case with a heavier stone burden.

In our case, we preferred to perform LP in consideration of heavy stone burden, and absence of an extrarenal pelvis, and an aberrant vessel crossing over renal pelvis, possibility of easy access to stones, and extraction of the stone as a single piece without resorting to fragmentation which might ensure complete stone-free rates.

The outcomes of LP were firstly published by Gaur et al. ${ }^{[17]}$ LP performed for the management of staghorn stones was also reported by Gaur et al. ${ }^{[18]}$. In a meta-analysis conducted in 2013, the authors considered PNL, and LP as safe, reliable, and effective treatment modalities in large solitary stones bigger than $2 \mathrm{~cm}$, and reported demonstrated shorter operative, and hospital stay times, lesser blood loss, and less frequent postoperative febrile states for PNL procedures. Stone-free rates were found to be 98.7 (158/160), and 89.4\% (153/171), respectively (p:0 .006) ${ }^{\left[{ }^{[19]} \mathrm{LP}\right.}$ can be a proper alternative in the presence of stones larger than $2 \mathrm{~cm}$ together with ureteropelvic junction stenosis, and in patients with anomalous kidneys, and in morbidly obese individuals where. ESWL, and other endourollogical interventions have lower procedural success rates. ${ }^{[19]}$

Thanks to the development in laparoscopic techniques, and instruments, and increasingly accumulating experiences of the surgeons in laparoscopic surgery, this minimally invasive approach has become a realistic alternative in the management of stone disease in anomalous kidneys. ${ }^{[20]}$

Laparoscopic method is a safe, and effective approach in the management of cases with horseshoe kidney, and renal pelvic stones larger than $2 \mathrm{~cm}$.

Informed Consent: Written informed consent was obtained from patient who participated in this case.
Peer-review: Externally peer-reviewed.

Author Contributions: Concept - E.Ö.; Design - E.Ö.; Data Collection and/or Processing - A.Ç., S.B.; Writer - E.Ö.; Other - A.M.B.

Conflict of Interest: No conflict of interest was declared by the authors.

Financial Disclosure: The authors declared that this study has received no financial support.

\section{References}

1. Salas M, Gelet A, Martin X, Sanseverino R, Viguier JL, Dubernard JM. Horseshoe kidney: the impact of percutaneous surgery. Eur Urol 1992;21:134-7.

2. Jones DJ, Wickham JE, Kellett MJ. Percutaneous nephrolithotomy for calculi in horseshoe kidneys. J Urol 1991;145:481-3.

3. Raj GV, Auge BK, Weizer AZ, Denstedt JD, Watterson JD, Beiko DT, et al. Percutaneous management of calculi within horseshoe kidneys. J Urol 2003;170:48-51.

4. Pitts WR Jr, Muecke EC. Horseshoe kidneys: a 40-year experience. J Urol 1975;113:743-6.

5. Bilen CY, Şahin A. Percutaneous nephrolithotomy in horseshoe kidneys. Turkish Journal of Urology 2006;32:495-9.

6. Lampel A, Hohenfeller M, Schultz-Lampel D, Lazica M, Bohnen K, Thürof JW. Urolithiasis in horseshoe kidneys: Therapeutic management. Urology 1996;47:182-6.

7. Nambirajan T, Jeschke S, Albqami N, Nambirajan T, Jeschke $\mathrm{S}$, Albqami $\mathrm{N}$, et al. Role of laparoscopy in management of renal stones: Single-center experience and review of literature. J Endourol 2005;19:353-8.

8. Tunc L, Tokgoz H, Tan MO, Kupeli B, Karaoglan U, Bozkirli I. Stones in anomalous kidneys: results of treatment by shock wave lithotripsy in 150 patients. Int J Urol 2004;11:831-6.

9. Sheir KZ, Madbouly K, Elsobky E, Abdelkhalek M. Extracorporeal shock wave lithotripsy in anomalous kidneys: 11-year experience with two second-generation lithotripters. Urology 2003;62:10-5.

10. Theiss M, Wirth MP, Frohmuller HG. Extracorporeal shock wave lithotripsy in patients with renal malformations. Br J Urol 1993;72:534-8.

11. Esuvaranathan K, Tan EC, Tung KH, Foo KT. Stones in horseshoe kidneys: Results of treatment by extracorporeal shock wave lithotripsy and endourology. J Urol 1991;146:1213-5.

12. Maheshwari PN, Bhandarkar DS, Shah RS, Andankar MG, Saple AL. Laparoscopy-assisted transperitoneal percutaneous nephrolithotomy for recurrent calculus in isthmic calix of horseshoe kidney. J Endourol 2004;18:858-61.

13. Mosavi-Bahar SH, Amirzarger MA, Rahnavardi M, Moghaddam SM, Babbolhavaeji H, Amirhasani S. Percutaneous nephrolithotomy in patients with kidney malformation. J Endourol 2007;21:520-4.

14. Gupta NP, Mishra S, Seth A, Anand A. Percutaneous nephrolithotomy in abnormal kidneys: single center experience. Urology 2009;73:710-4.

15. Rodrigues Netto N Jr, Lemos GC, Fiuza JL. Colon perforation following percutaneous nephrolithotomy. Urology $1988 ; 32: 223-4$ 
16. Goswami AK, Shrivastava P, Mukherjee A, Sharma SK. Management of colonic perforation during percutaneous nephrolithotomy in horse-shoe kidney. J Endourol 2001;15:989-91.

17. Gaur DD, Agarwal DK, Purohit KC, Darshane AS. Retroperitoneal laparoscopic pyelolithotomy. J Urol 1994;151:927.

18. Gaur DD, Trivedi S, Prabhudesai MR, Gopichand M. Retroperitoneal laparoscopic pyelolithotomy for staghorn stones. J Laparoendosc Adv Surg Tech A 2002;12:299-303.
19. Wang X, Li S, Liu T, Guo Y, Yang Z. Laparoscopic Pyelolithotomy Compared to Percutaneous Nephrolithotomy as Surgical Management for Large Renal Pelvic Calculi: A Meta-Analysis. Eur Urol 2013;190;888-93.

20. Hruza M, Schulze M, Teber D, Gözen AS, Rassweiler JJ. Laparoscopic techniques for removal of renal and ureteral calculi. J Endourol 2009;23:1713-8. 